Published in final edited form as:

Org Lett. 2005 July 7; 7(14): 3053-3056.

\title{
Total Synthesis of (+)-Dactylolide
}

\author{
Carina C. Sanchez and Gary E. Keck \\ Department of Chemistry, University of Utah, 315 South 1400 East RM 2020, Salt Lake City, Utah \\ 84112-0850 keck@chemistry.utah.edu
}

\begin{abstract}
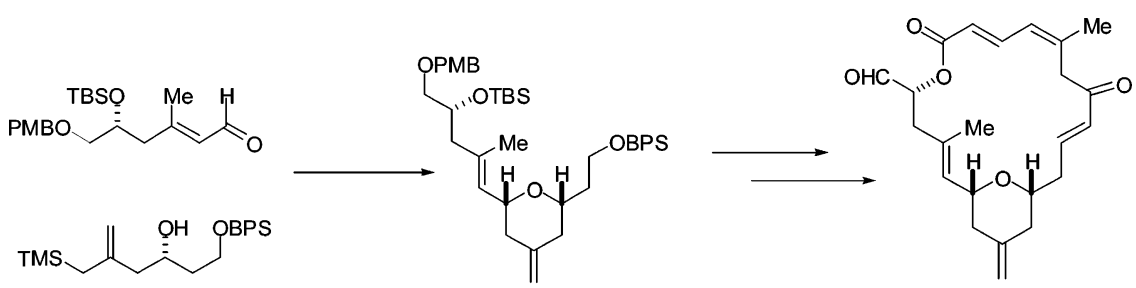

(+)-Dactylolide

The development of an approach leading to the total synthesis of dactylolide is described. The key features of this route include a catalytic asymmetric allylation, a diastereoselective pyran annulation, and a Horner-Wadsworth-Emmons macrocyclization.
\end{abstract}

Dactylolide (1) was one of the many cytotoxic metabolites isolated from the Vanuatu sponge Dactylospongia sp. by Riccio and co-workers in $2001 .^{1}$ Dactylolide was shown to have cytotoxicity toward L1210 cell lines (63\% inhibition at $3.2 \mu \mathrm{g} / \mathrm{mL})$ and SK-OV-3 cell lines (40\% inhibition at $3.2 \mu \mathrm{g} / \mathrm{mL}$ ). Spectroscopic investigations led to the suggestion of structure 1 (Figure 1) for this material, although the configuration at $\mathrm{C}_{19}$ was not established. The major architectural elements of dactylolide consist of a highly unsaturated but moderately functionalized 20-membered macro-lactone, a 2,6-cis-disubstituted methylene tetrahydropyran, and two trisubstituted olefins.

In 2002, Smith and Safonov reported the results of synthetic investigations on zampanolide 2 (2) and dactylolide which established the relative configuration of the dactylolide stereocenters and culminated in the first total synthesis of the molecule. ${ }^{3}$ Hoye and Hu later disclosed a synthesis of (-)-dactylolide as a precursor to zampanolide. ${ }^{4}$ Most recently, during the preparation of this manuscript, the groups of Floreancig as well as Jennings have both reported total syntheses of dactylolide. 5,6

Our interest in dactylolide stemmed from its molecular structure. Recent work in our laboratories has provided an exceptionally facile access to stereodefined 2,6-cis-4-methylene tetrahydropyrans. ${ }^{7}$ We wished to further explore the scope of this reaction by exploring the use of $\alpha, \beta$-unsaturated aldehydes in the transformation, an issue which would by necessity be addressed in the context of a synthesis of dactylolide.

The route chosen for experimental investigation is outlined schematically in Figure 2. We envisioned application of a Horner-Wadsworth-Emmons macrocyclization to close the 20membered macrolactone. The phosphonate required for this step was in turn envisioned to arise from another Horner-Wadsworth-Emmons reaction between aldehyde $\mathbf{4}$ and $\beta$ -

Supporting Information Available: Full experimenal details as well as spectral data for all new compounds. This material is available free of charge via the Internet at http://pubs.acs.org. 
ketophosphonate $\mathbf{5}$. The pyran subunit $\mathbf{4}$ would be prepared using the pyran annulation reaction as previously mentioned. We anticipated that the pyran annulation reaction between the hydroxy allylsilane 6 and $\alpha, \beta$-unsaturated aldehyde 7 would lead to the desired 4 -methylene tetrahydropyran with the required cis stereochemistry. For the preparation of the enal $\mathbf{7}$, we planned to use the catalytic asymmetric allylation (CAA) based trisubstituted olefin synthesis previously developed in our laboratories. ${ }^{8}$ The other component necessary for the pyran annulation reaction, hydroxy allylsilane $\mathbf{6}$, would arise from a CAA reaction of the appropriate aldehyde with the known 2-(trimethylsilylmethyl)allyltri- $n$-butylstannane reagent 15.7,9

The preparation of aldehyde $\mathbf{7}$ commenced with the CAA reaction of aldehyde 9 with the functionalized stannane 10, to give the desired $(R)$-homoallylic alcohol $\mathbf{8}$ in $75 \%$ yield and 93\% ee after chromatographic purification (Scheme 1). After conversion of the free hydroxyl to the corresponding silyl ether $\mathbf{1 1}$ by reaction with TBSCl and imidazole (96\% yield), an isomerization was employed to secure the $E$ unsaturated ester 12 (97\%, 32:1 E/Z).

This isomerization is an exceptional reaction and deserves some comment. We believe that the high level of stereo-selectivity observed is a kinetic phenomenon associated with a preferred pathway for formation of the $\mathrm{U}$ shaped internally chelated enolate anion with sodium as counterion. The use of DBU to effect this transformation resulted in a 9:1 mixture. After extended reaction times, the sodium hydride process also afforded a 9:1 mixture.

With the $E$ stereochemistry of the unsaturated ester secured, reduction to the alcohol was effected using LAH (93\% yield). Oxidation using the method of Ley (TPAP-NMO, 91\% yield) then afforded the $\alpha, \beta$-unsaturated aldehyde needed for the pyran annulation. The preparation of the hydroxyallylsilane component (Scheme 2) for the pyran annulation was effected via a catalytic asymmetric allylation reaction using stannane $\mathbf{1 5}$ and $(S)$-BITIP catalyst to afford the desired hydroxy allylsilane 6 in $91 \%$ yield and with $95 \%$ ee. $^{7}$

The stage was now set for the pyran annulation reaction. We were delighted to find that the pyran annulation between aldehyde $\mathbf{7}$ and hydroxy allylsilane $\mathbf{6}$ proceeded in excellent yield $(85 \%)$ and provided the desired pyran 16 as a single diastereomer (by ${ }^{1} \mathrm{H}$ and ${ }^{13} \mathrm{C} \mathrm{NMR}$ ). This pyran is thus available to us in six steps with an overall yield of $50 \%$ from aldehyde 9 . Selective deprotection of the BPS group followed using TBAF/AcOH. ${ }^{10}$ Oxidation using TPAP/NMO then provided the sensitive pyran aldehyde $\mathbf{1 7}$.

The synthesis of the $\beta$-ketophosphonate 5 began with intermediate 18 (Scheme 3). ${ }^{11}$ DIBAL$\mathrm{H}$ reduction of the ester to the alcohol, followed by protection as the BPS ether generated the disilyl ether. Selective deprotection of the TBS ether was accomplished using CSA/MeOH. This three-step sequence was carried out in 75\% yield. Oxidation of the resulting alcohol 19 was problematic and the only reagent found to work well in this case was $\mathrm{CrO}_{3} /$ pyridine. The use of PCC, Dess-Martin periodinane, TPAP-NMO, and PDC all failed, a result which may be attributed to the sensitive nature of the desired $\beta-\gamma$ unsaturated system. Fortunately, addition of the lithiate of methyl dimethyl phosphonate into this aldehyde occurred without incident. Oxidation of the resulting alcohol using Dess-Martin periodinane then afforded the desired $\beta$-ketophosphonate $\mathbf{5}$ (70\% over three steps).

The $\beta$-ketophosphonate $\mathbf{5}$ and the aldehyde $\mathbf{1 7}$ were then united by means of a HornerWadsworth-Emmons reaction (Scheme 4). Many different conditions were examined to effect this transformation, and the use of Paterson's $\mathrm{Ba}(\mathrm{OH})_{2}$ procedure $^{12}$ proved superior to reactions using more standard bases $\left(\mathrm{KO} \mathrm{B}^{t} \mathrm{Bu}\right)$ or reaction under Masamune's conditions. ${ }^{13} \mathrm{We}$ were delighted to find that the Horner-Wadsworth-Emmons reaction worked extremely well to generate the desired enone $\mathbf{2 0}$ in a $79 \%$ yield. 
At this point, we became concerned about potential problems associated with the presence of the keto group at $\mathrm{C}_{7}$. We reasoned that the acidity of the protons $\alpha$ to the ketone at $\mathrm{C}_{6}$ would be significantly enhanced since they are also $\gamma$ with respect to the $\alpha, \beta$-unsaturated aldehyde. If the ketone were to be left unprotected, the anticipated ease of removal of these protons could negatively impact upon the desired Horner-Wadsworth-Emmons macrocyclization.

To preclude these potential problems, we decided to reduce and protect the ketone. The next issue that arose was the choice of protecting group for the alcohol. In looking at the projected synthesis, it can be seen that the alcohol at $\mathrm{C}_{20}$ was protected as a PMB ether. This PMB group must be removed and the resulting alcohol oxidized. The alcohol at $\mathrm{C}_{7}$ would also have to be deprotected and oxidized in one of the penultimate steps of the synthesis. Thus, we elected to protect this alcohol as the PMB ether in hopes that we could deprotect and oxidize both alcohols in the same operation.

Luche reduction of the ketone provided the alcohol which was immediately subjected to PMB protection (Scheme 5). We examined a variety of methods for installing the PMB ether; however most of these failed or gave poor yields. Use of the PMB imidate and triflic acid resulted in decomposition of the alcohol substrate. Use of $\mathrm{KH}$ and $\mathrm{PMBBr}$ resulted in only trace amounts of product formation. It was ultimately found that KHMDS, PMBBr, and triethylamine worked extremely well to provide the desired product $\mathbf{2 1}$ in $94 \%$ yield over two steps. 14

With this operation implemented, attention was turned toward forming the phosphonoaldehyde needed for the Horner-Wadsworth-Emmons macrocyclization (Scheme 5). Selective deprotection of the TBS ether ensued using PPTs in EtOH in 74\% yield. Other methods such as $\mathrm{HF} \bullet$ pyr and $\mathrm{CSA} / \mathrm{MeOH}$ provided diminished yields.

Acylation of the alcohol with diethylphosphonoacetic acid was now required. The conditions used for this reaction were those of the modified Keck-Boden macrolactonization that we had reported on previously. ${ }^{15}$ The phosphonate product was expected to be (and indeed was) very polar, therefore utilizing a polymer-bound DCC (PS-DCC) rather than DCC itself would simplify the workup as well as isolation and purification of the phosphonate. This acylation was found to occur very rapidly using the PS-DCC reagent in combination with DMAP and DMAP hydrochloride to provide a quantitative yield of the desired phosphono ester. Our attention now turned to deprotection of BPS ether 22 (Scheme 6). This was easily accomplished using $\mathrm{HF}$ and pyridine to give the free alcohol in $74 \%$ yield. Oxidation of the resulting alcohol to the aldehyde was accomplished using TPAP-NMO.

With the phosphono aldehyde successfully synthesized, the Horner-Wadsworth-Emmons macrocyclization could now be attempted. The phosphono-aldehyde was subjected to 1.2 equivalents of $\mathrm{NaHMDS}$ at $-78{ }^{\circ} \mathrm{C}$ with subsequent warming to $0{ }^{\circ} \mathrm{C}$. 2,16 This led to the desired macrocycle $\mathbf{2 3}$ in a $60 \%$ isolated yield. Only removal of the PMB ethers and oxidation were now required to complete the synthesis of dactylolide.

Deprotection of both PMB ethers proceeded smoothly by reaction with DDQ (84\% yield), and Dess-Martin oxidation of the resulting diol followed to generate the natural product dactylolide. This double oxidation also occurred without incident and in high (91\%) yield. Our synthetic dactylolide displayed spectral and analytical data in excellent agreement with those previously reported for the natural material as well as with data described from previous synthetic efforts. 17

In conclusion, dactylolide was synthesized in 18 steps (longest linear sequence) from aldehyde 9 (20 linear steps from commercially available 2-butene-1,4-diol) and in 7.1\% overall yield. This is the highest yielding synthesis reported to date. 


\section{Supplementary Material}

Refer to Web version on PubMed Central for supplementary material.

\section{Acknowledgment}

Financial support from the National Institutes of Health (through GM-28961) and by Pfizer, Inc., in the form of a Diversity in Organic Chemistry Fellowship (to C.C.S.) is gratefully acknowledged.

\section{References}

1. Cutignano A, Bruno I, Bifulco G, Casapullo A, Debitus C, Gomez-Paloma L, Riccio R. Eur. J. Org. Chem 2001:775.

2. Tanaka J, Higa T. Tetrahedron Lett 1996;37:5535.

3. (a) Smith AB III, Safonov IG, Corbett RM. J. Am. Chem. Soc 2001;123:12426. [PubMed: 11734051]

(b) Smith AB III, Safonov IG. Org. Lett 2002;4:635. [PubMed: 11843610]

4. Hoye TR, Hu M. J. Am. Chem. Soc 2003;125:9576. [PubMed: 12904009]

5. Floreancig PE, Aubele DL, Wan S. Angew. Chem., Int. Ed 2005;44:3485.

6. Jennings MP, Ding F. Org. Lett 2005;7:2321-2324. [PubMed: 15932188]

7. Keck GE, Covel JA, Yu T, Schiff T. Org. Lett 2002;4:1189. [PubMed: 11922815]

8. Keck GE, Yu T. Org. Lett 1999;1:289. [PubMed: 10822564]

9. (a) Kang K-T, Hwang SS, Kwak WY, Yoon UC. Bull. Korean Chem. Soc 1999;20:801. (b) Clive DLJ, Paul CC, Wang Z. J. Org. Chem 1997;62:7028. The 2-(chloromethyl)allylsilane precursor to 15 is commercially available (Aldrich)

10. Higashibayashi S, Shinko K, Ishizu T, Hashimoto K, Shirahama H, Nakata M. Synlett 2000:1306.

11. Still WC, Gennari C, Nogues JA, Pearson DA. J. Am. Chem. Soc 1984;106:260.

12. (a) Paterson I, Yeung K-S. Tetrahedron Lett 1993;34:5347. (b) Paterson I, Yeung K-S, Smaill JB. Synlett 1993:774.

13. Masamune S, Roush WR, Sakai T, Blanchette MA, Choy W, Davis JT, Essenfeld AP. Tetrahedron Lett 1984;25:2183.

14. Roush WR, Holson EB. Org. Lett 2002;4:3719. [PubMed: 12375927]

15. Keck GE, Sanchez CC, Wager CA. Tetrahedron Lett 2000;41:8673.

16. We originally investigated the use of a macrolactonization reaction to close the 20-membered macrolactone. Many macrolactonization methods failed to provide the desired macrolactone. Further details will be provided in a full account of this work.

17. The optical rotation that we measured was $[R]^{20} \mathrm{D}=+134(c=0.065, \mathrm{MeOH})$. Smith reported a rotation of $+235(c=0.52, \mathrm{MeOH})$. Hoye reported a rotation of $-128(c=0.39, \mathrm{MeOH})$ for the unnatural enantiomer of dactylolide. Floreancig reported an optical rotation of $+163(c=0.29$, $\mathrm{MeOH})$. Jennings reported a rotation of $-136(c=1.2, \mathrm{MeOH})$ for the unnatural enantiomer of dactylolide. The optical rotation reported for the natural material is $+30(c=1.0, \mathrm{MeOH})$. The reason for this deviation in rotations is unclear, but we believe an explanation may be found in the presence of the highly conjugated and enolizable ketone and ester functions in the $\mathrm{C}_{1}-\mathrm{C}_{10}$ region. Enolization could occur using a proton at $\mathrm{C}_{6}, \mathrm{C}_{10}$, or both. Enol formation using the $\mathrm{C}_{5}$ methyl group is also possible. The precise enol content and composition in turn could depend on the exact batch of solvent used, the history of the sample, the polarimeter cell, etc. Since such highly conjugated enols would be expected to have large rotations, it can be seen that even small variations in enol content could lead to large variations in the measured optical rotation. 


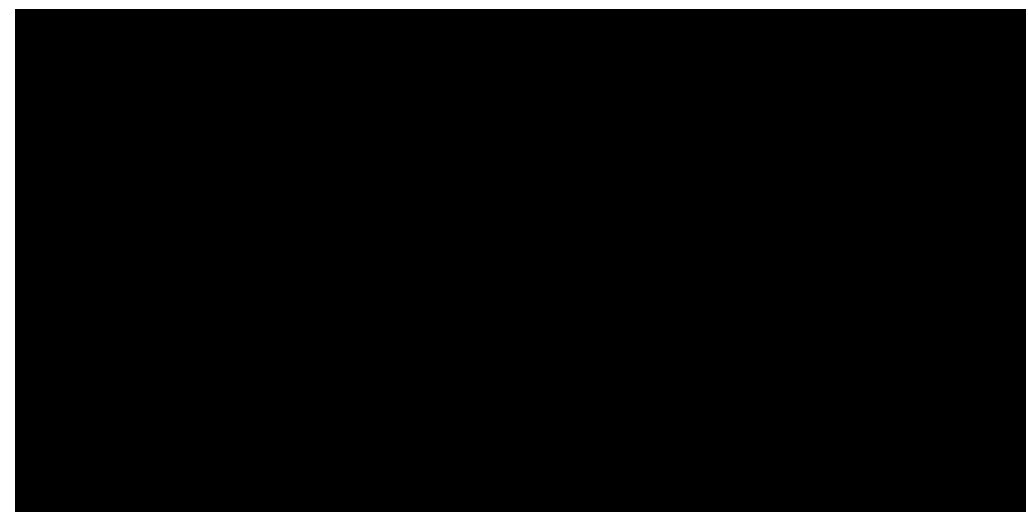

Figure 1.

(+)-Dactylolide and (-)-zampanolide. 


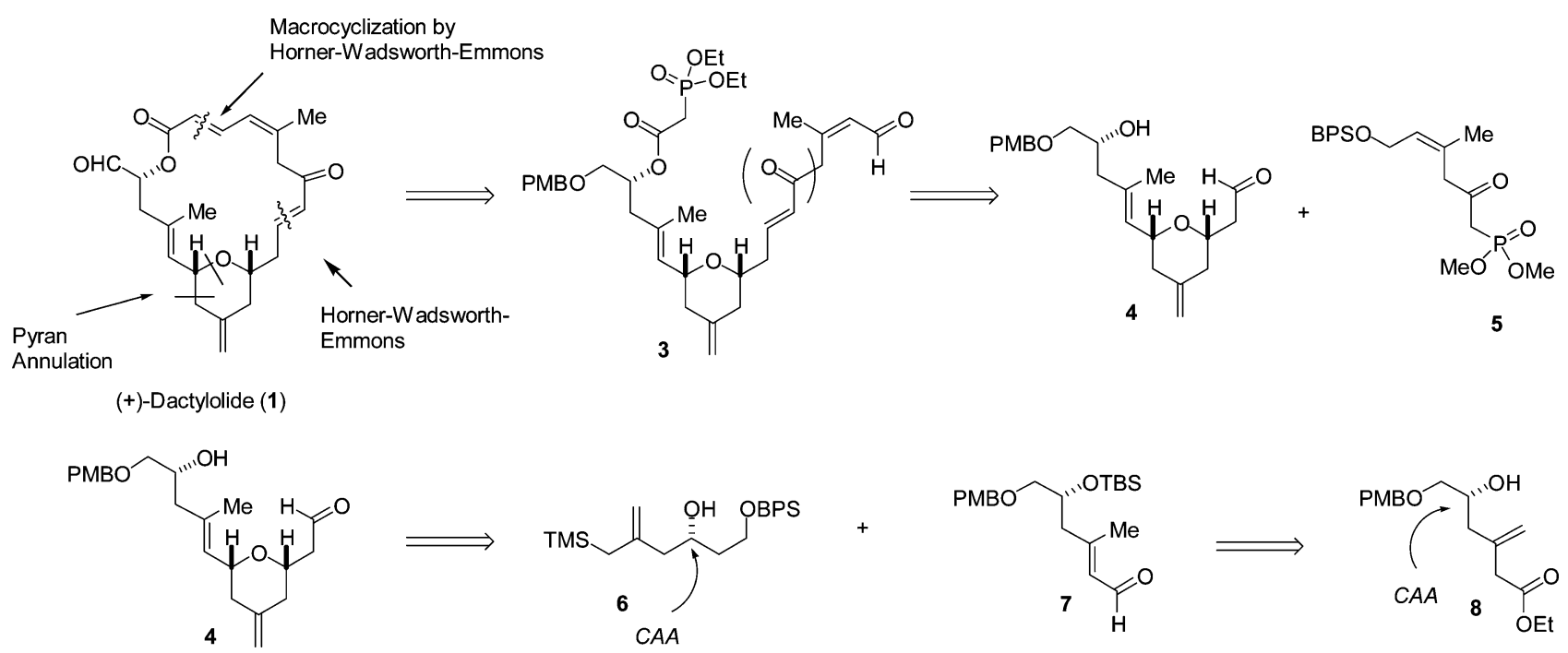

Figure 2.

Retrosynthetic analysis. 
Scheme 1.

Synthesis of $\alpha, \beta$-Unsaturated Aldehyde 7 
Scheme 2.

Pyran Annulation 


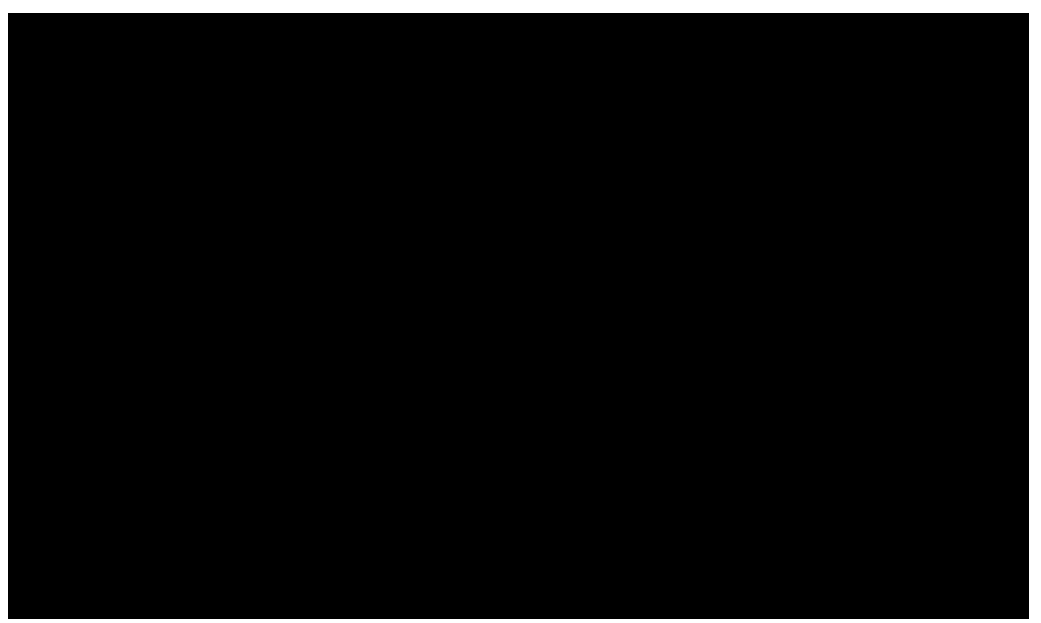

Scheme 3.

Synthesis of $\beta$-Ketophosphonate $\mathbf{5}$ 


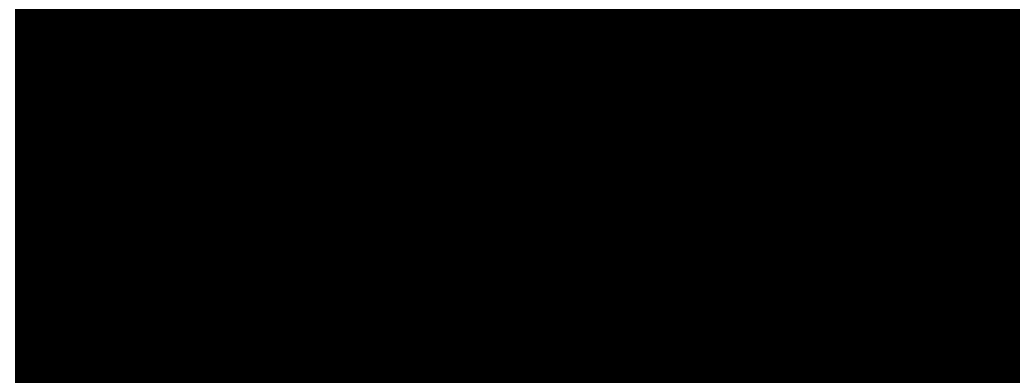

Scheme 4.

Horner-Wadsworth-Emmons Reaction 


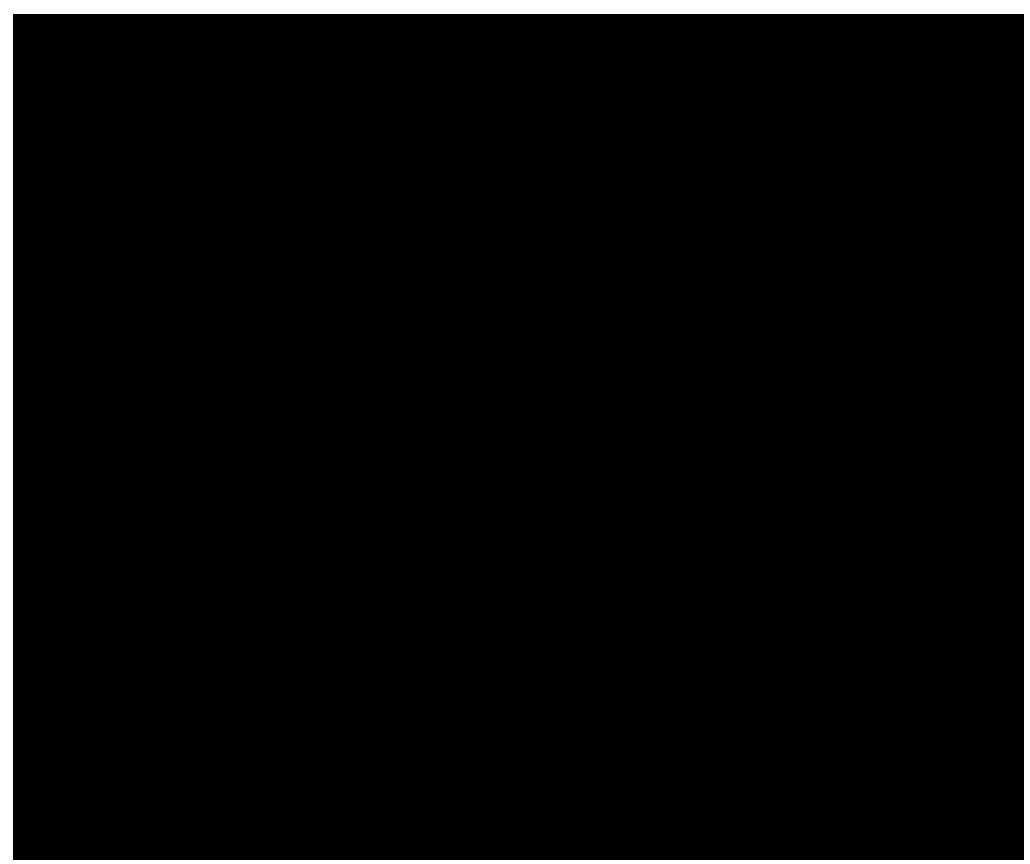

Scheme 5.

Preparation of $\mathbf{2 2}$ 


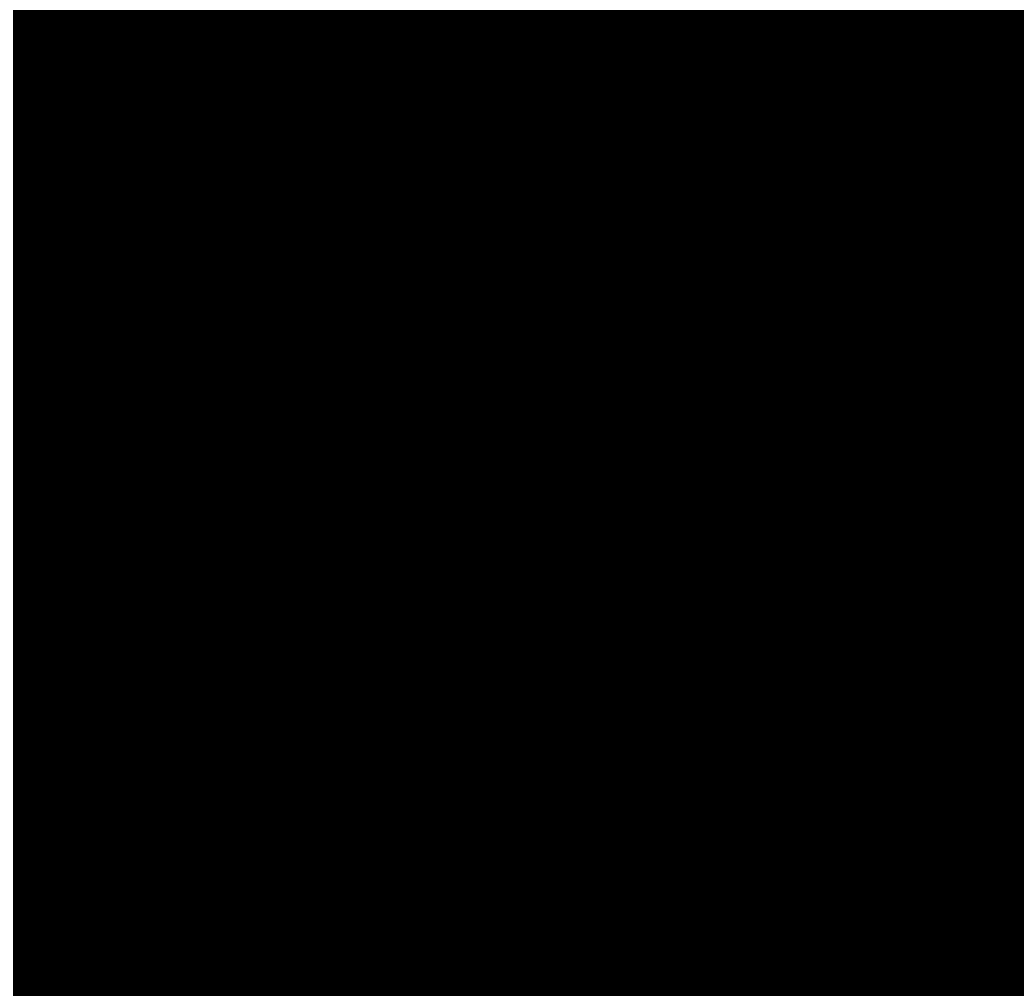

Scheme 6.

Completion of the Synthesis 